In No. 5 of the Revue générale des Sciences (March I5, p. I77) M. G. Renaudot makes the interesting suggestion that the periodicity of comets, or of Halley's comet especially, was known and recognised by the ancient Hebrews. He bases this suggestion on a passage in the Talmud, where one of two voyagers explains that he has laid in a stock of flour, rather than bread, because "There is a very bright star which appears every seventy years and which deceives navigators. Thinking that she may surprise us during this voyage, and so prolong our journey, I have provided the flour." M. Renaudot gives reasons why the expected object should be considered as a comet, wather than as a long-period variable, for instance, explains that 70 instead of 75 is in accordance with the habit of giving round numbers, and states that the existence of the two important personages between whom the dialogue took place is vell attested historically.

A second edition of Prof. Turner's British Association address on "Halley's Comet" has just been issued by the Clarendon Press at the price of $1 s$. net.

EPHEMERIS FOR EROS, Igro.-To facilitate observations of Eros during the coming opposition, Prof. Wendell has computed an ephemeris, which is published in Circular No. 153 of the Harvard College Observatory. Unfortunately, the planet will not be observable in these latitudes, its declination at opposition (May 23) being $46^{\circ} 3 \mathrm{r}^{\prime}$ S., but, as its orbit and light-variations are so peculiar, it is hoped that a number of observations will be secured at southern observatories.

Prof. Doberck's Double-star Observations.--In continuation of a list which appeared in Nos. $4327-8$ of the Astronomische Nachrichten, Prof. W. Doberck now publishes his observations of a great number of doubles, at Sutton during 1909, in Nos. 4394-5 of the same journal. Each observation is recorded separatcly, and the positionangle and distance of each pair are given for the mean epoch of observation.

Daniel's CoMet, igoge.-A photograph of Daniel's comet (Ig09e) was secured by Dr. Wolf on February 28 , when the comet's magnitude was 15.0 . It now appears that this comet belongs to the Jupiter, and not to the Uranus, family of comets, as was at first suspected.

\section{THE NATIONAL PHYSICAL LABORATORY IN Igog.}

THE general board of the National Physical Laboratory held their annual meeting at the laboratory on Friday last, March 18, when the report of the work done during 1909 was presented, and the programme of work proposed for the year I9I0 was approved. The chair was taken by Sir Archibald Geikie, as president of the Royal Society, and Lord Rayleigh, chairman of the executive committee, was also present. A large number of guests were invited to inspect the various departments of the laboratory.

Two new branches of the work claim attention this year. The first of these is the national experimental tank for experiments on ship models, which is being constructed at a cost of about $20,000 l$., provided by the generosity of Mr. A. F. Yarrow. A maintenance fund for carrying on the work of the tank for the first ten years has also been provided with the aid of the Institution of Naval Architects. With regard to the details of the working of the tank, assistance will be given, under a scheme printed in the iaboratory report, by an advisory committee composed of members nominated by the Institution of Naval Architects and by the executive committee of the laboratory.

The tank itself, and the office buildings and workshops 1equired, are now nearly completed. The length of the tank is 500 feet at the full depth of $12 \frac{3}{2}$ feet, and the width 30 feet. At the north end are docks for receiving the models, while at the south end is a shallow "beach" for breaking the waves. As was shown by Dr. Glazebrook in a report presented in March, 1909 , to the Institution of Naval Architects, models up to 20 feet in length and 3 feet in breadth can be tested in a tank of the width stated without any appreciable effect on the results due to the sides.

The models will be towed along by a carriage. electrically driven, spanning the tank and running on rails on either No. 2108 , VOI. 83$]$ side. This carriage carries the observers and dynamometers. The models will usually be made of paraffin wax and the equipment will include special model-cutting machinery. None of this apparatus, however, is ye installed, and we hope, at a later date, to give a more detailed account of the tank and of the special apparatus employed.

i he second large development of the work during 1909 is the formation of a division for research in aëronautics. This work has been undertaken in accordance with the announcement made by the Prime Minister in the House of Commons on May 5, 1909, and is under the general superintendence of the Advisory Committee for Aëronautics then appointed. Rapid progress has been made during the year with the provision of the necessary equipment for the experimental work at present planned. This includes an air channel 4 feet square in section by 20 feet long for general work in aërodynamics, a whirling table 60 feet in diameter for propeller testing, in a special building 80 feet square; dynamometers for motor testing, with arrangements for an air blast for air cooling; and two wind towers for work on a large scale in the open. All this apparatus has been erected, and experiments have been for some time in progress. The division is under the charge of Dr. Stanton as superintendent of the engineering department, and his great experience on the subject of wind pressure will be especially valuable. To provide the increased accommodation necessary, two more bays have been added to the engineering building.

The testing of balloon fabrics also constitutes an important branch of the work. Tensile and bursting tests have been carried out in the engineering department, while in the chemical department a special apparatus has been devised for the determination of the permeability to hydrogen. We may, perhaps, be able on another occasion to give further particulars of the aëronautical equipment.

Turning now to the physics department, in the electrical standards division good progress has been made with the erection of the Lorenz apparatus for the determination of the ohm in absolute measure, and this is now nearly complete. The coils, wound on marble cylinders, have been made in the laboratory; the main part of the machine, by the kindness of Sir Andrew Noble, has been constructed at Elswick. The determinations to be made with this will be the chief work in this division during the current year. With regard to standard cells, a research has been in progress to determine the limits of temperature between which cadmium amalgams of various concentration can be usefully employed, the results of which were communicated to the Physical Society by Mr. F. E. Smith in a recent paper. The general conclusion arrived at is that an amalgam containing $12 \frac{1}{2}$ per cent. of cadmium cannot safely be used below $12^{\circ} \mathrm{C}$., and the substitution of a ro per cent. amalgam is recommended. This can be relied upon to give constant results at a definite temperature for all temperatures between $0^{\circ}$ and $5 \mathrm{I}^{\circ} \mathrm{C}$.

We have previously made reference to the new order in council lately issued relative to the electrical units, the outcome of the work of the International Conference in London in 1908. To complete the work of the conference, representatives from the chief standardising laboratories are to meet at Washington shortly to continue jointly the researches necessary to decide on a definite value for the E.M.F. of the Weston cell.

Another matter in which international cooperation is being arranged is the question of the methods of measuring hysteresis and eddy loss in steel sheet. A modification of the Epstein method has recently been devised by the Bureau of Standards which appears to give accurate results, and investigations relative to this question have been in progress at the laboratory.

In the electrotechnics division much attention has been given to perfecting the equipment for alternating-current measurements. Features of special interest are the noninductive water-cooled tube resistances, described in a paper communicated to the Institution of Electrical Engineers, and the quadrant electrometer for use as an alternating-current wattmeter. The 100,000 -volt transformer equipment has been completed, and has been employed in an investigation into the properties of different varieties of ebonite, while a research on insulating materials is in progress. In the photometry section a considerable 
amount of work has been done towards setting up substandards for use in measurements of metallic filament lamps. The determination of the candle-power of these in terms of the pentane standard involves a comparison between lights of different colour, and in the process of stepping up as many observers as possible must be employed to obtain a representative mean.

Early in the past year an agreement was arrived at between the authorities in America, France, and this country as to a common light unit, the American unit being altered by $\mathrm{I} \cdot 6$ per cent. to bring it into agreement with the British unit expressed in terms of the ro-candle Harcourt pentane lamp.

In the thermometry division the work has consisted in great measure of improvements in the equipment, especially with the view of the extension of the work on the fundamental gas scale to higher temperatures. It is hoped that a useful material for gas-tight vessels has been obtained, but further progress required power for heating larger furnaces, which has now been provided.

In the metrology division an interesting experiment is being tried in the use of silica as a material for standards of length. The advantages are a low coefficient of expansion and small thermal hysteresis, i.e. the temporary change in length due to a cycle of temperature change is small. A standard has been constructed with flat and parallel end slabs fused into a hollow cylindrical rod, the slabs being platinised to receive the divisions. The study of this standard will be continued during the present year.

Important additions have been made to the sets of standard screw gauges in the possession of the laboratory. These now comprise complete series of British standard Whitworth threads, British standard fine threads, British standard electrical conduit gauges, and B.A. threads. They have been constructed by Armstrong, Whitworth and $\mathrm{Co}$. to the dimensions laid down by the Engineering Standards Committee. Two large machines for pitch and diameter measurements are also being constructed at Openshaw.

The 50-metre mural base for verification of surveying tapes has been completed. The length of this base is stepped out against a 4-metre standard bar, itself determined against the standard metre. Another important piece of work has been the re-erection of the Blythswood ruling machine for puling diffraction gratings. By shifting the periodic error connecting cam from one end of the screw to the other, the length of grating which can be ruled has been increased from 5 to 8 inches. The exact setting of the periodic error cam alone remains to be done to enable the ruling of gratings to be commenced.

A useful piece of work in the optics division has been the devising of a new apparatus for testing photographic shutters. The method is essentially that of Sir Wm. Abney, with the use of a vibration galvanometer in place of a siren as a time recorder.

In the engineering department a large number of researches are in progress. Dr. Stanton is continuing his wind-pressure work, as well as the research on the resistance of materials to alternating stresses of high frequency. Some very interesting results have been obtained with regard to the heat transmission and friction of air currents in pipes, and a paper on the resistance of plates and models in a uniform current of water was communicated to the Institution of Naval Architects. The water channel used for these experiments has been utilised also for work in connection with aëronautics, and gives results closely comparable with those obtained in an air channel, allowance, of course, being made for the difference in density. valuable paper by $\mathrm{Mr}$. Bairstow on the elastic limits of material under alternating stress has been published in the Philosophical Transactions, and contains interesting experimental conclusions relative to the theory of fatigue. Another research of importance which is in progress relates to the strength and efficiency of welded joints, from which the preliminary conclusions have been reached that the material at a welded joint is often in a dangerously brittle state, and that a long weld is essential to secure even moderately good results.

In the department of metallurgy and metallurgical chemistry, the work done for the Alloys Research Committee of the Institution of Mechanical Engineers was embodied in the ninth report, on some alloys of copper, aluminium, and manganese, presented to the institution early in 1909. Further work on the light alloys of aluminium is in progress. The eutectics research, on which a first communication appeared in 1908 in the Philosophical Transactions, has been continued, attention being especially directed to the mode of solidification of eutectic alloys. A preliminary account of an investigation into the effects of strain at high temperatures, recently published in the Proceedings of the Royal Society, presents features of interest. It was established that deformation by intra-crystalline slip occurs at temperatures up to $I \mathrm{IOO}^{\circ} \mathrm{C}$., while the three allotropic modifications of iron known as $\alpha, \beta$, and $\gamma$ iron showed marked differences in the effects of strain. A number of cases of failure in practice have been investigated, and in connection with these a systematic study is being made of the modes of fracture of steel.

The work of the observatory departments of the laboratory, at Kew and Eskdalemuir, is of a distinct character, and need not be referred to now in detail. Mention must, however, be made of the admirable piece of work completed by Dr. Chree, in the discussion of the magnetic curves of the National Antarctic Expedition of 1902-4 printed in the volume of "Magnetic Observations" issued by the Royal Society early last year.

\section{INSTITUTION OF NAVAL ARCHITECTS.}

THE spring meetings of the Institution of Naval Architects commenced on Wednesday, March 16 , in the rooms of the Royal Society of Arts. The institution has now completed its first fifty years of existence, and proposes to celebrate its jubilee by special meetings commencing on July 4. The council also recommended that the present time is favourable for applying for incorporation under a Royal charter, an opinion which was endorsed by the members at the Thursday meeting. A presidential address was delivered by Earl Cawdor, and premiums were awarded to Dr. T. E. Stanton and Mr. H. C. Anstey for papers, respectively, on the resistance of thin plates and models in a current of water, and on the application of internal-combustion engines for marine propulsion. Thirteen papers in all were presented at the meetings, abstracts from some of which we give below.

A systematic series of experiments on wake and thrust deduction has been carried out recently at the experimental tank of Messrs. John Brown and Company's establishment at Clydebank, and form the subject of a paper contributed by Mr. W. J. Luke. Experiments were made with twin and with single screws, and in all cases where twin screws were run the experiments were made in both directions of rotation. The work involved the carrying out of at least 2000 experiments. The effective horse-power may be expressed as the product of the thrust horse-power and the hull efficiency, the latter quantity being the product $(\mathrm{I}+v)(\mathrm{I}-t)$, where $z$ is the wake fraction and $t$ is the fraction of the total thrust by which the tow-rope resistance is less than the thrust exerted by the screw when propelling the ship. The experiments were directed towards determining the variations in $w$ and $t$ when (a) spced, (b) diameter, and (c) pitch ratio were varied. With naked models a decrease in wake fraction is evident with an increase of speed; changes which appeared for variations in diameter might be as much owing to alterations in clearance; variation in pitch had little or no effect on either of the hull-efficiency elements.

Prof. B. Hopkinson, in his paper on the measurement of shaft horse-power by torsion-meters, directed attention to the need for further experimental work on full-sized shafts with the view of ascertaining whether twist may be produced by means of a longitudinal push or pull. Such would imply, if no torque be applied, a peculiar structure of the shaft, which might be described as a helical arrangement of the fibres. Mr. C. E. Stromeyer gave results of his observations of the brittleness of mild steel due to nitrogen. It has not yet been possible to combine nitrogen with steel by merely heating the two together, but this may be effected by heating steel in an atmosphere of ammonia. Ammonia may be present in blast furnaces if 